\title{
Autoantibodies to the Ribosomal P Proteins React with a Plasma Membrane-related Target on Human Cells
}

\author{
Eugen Koren, ${ }^{\star *}$ Marianne Wolfson Reichlin, ${ }^{\star}$ Mirna Koscec, ${ }^{\star}$ Robert D. Fugate, ${ }^{\star}$ and Morris Reichlin** \\ *Arthritis and Immunology Research Program, Oklahoma Medical Research Foundation, Oklahoma City, Oklahoma, 73104; and \\ ${ }^{\ddagger}$ Oklahoma University Health Sciences Center, Department of Medicine, Oklahoma City, Oklahoma 73104
}

\begin{abstract}
Autoantibodies to ribosomal P-proteins are present in 12-16\% of patients with systemic lupus erythematosus and are associated with neuropsychiatric disease. As the ribosomal P proteins are located in the cytoplasm, the pathogenic effects of their cognate autoantibodies are unclear. In this study affinitypurified anti-P autoantibodies were used to explore the cell surface of several types of human and animal cells. Immunofluorescence as well as EM immunogold analysis demonstrated, on the surface of human hepatoma cells, the presence of an epitope that is antigenically related to the immunodominant carboxy terminus of P-proteins. The presence of this epitope was also demonstrated on the surface of human neuroblastoma cells and, to a lesser extent, on human fibroblasts. Furthermore, the Western blot technique revealed in purified human and animal plasma membranes a 38-kD protein that is closely related or identical with ribosomal $P_{0}$ protein. The availability of reactive $P$ peptide on the surface of cells makes possible the direct effect of autoantibodies on the function and viability of cells that express this antigenic target. This delineates one of the possible impacts of anti-P antibodies in disease expression. (J. Clin. Invest. 1992. 89:1236-1241.) Keywords: ribosomal $P$ • autoantibodies - neuropsychiatric disease - neuroblastoma cells • hepatoma cells
\end{abstract}

\section{Introduction}

The sera of patients with systemic lupus erythematosus (SLE) contain autoantibodies to ribosomal P-proteins in 12-16\% of cases $(1,2)$. These highly conserved proteins comprise $P_{0}, P_{1}$ and $P_{2}$ molecules corresponding to sizes of 38,19 , and $17 \mathrm{kD}$, respectively (3-7). P-proteins are acidic phosphoproteins primarily associated with $60 \mathrm{~S}$ ribosomal subunit in eukaryotic cells although their presence in ribosome free cytoplasm has also been reported $(5,8)$. Most of SLE anti-P autoantibodies cross-react with $P_{0}, P_{1}$ and $P_{2}$ due to a common determinant present at the carboxy terminus of all three proteins. This epitope is confined within the 22 carboxy-terminal amino acids, the sequence of which is identical in $\mathrm{P}_{0}, \mathrm{P}_{1}$, and $\mathrm{P}_{2}$ proteins as well as in eL12 and eL12' Artemia salina proteins commonly

Address reprint requests to Dr. Morris Reichlin, Arthritis \& Immunology Research Program, Oklahoma Medical Research Foundation, 825 NE 13th St., Oklahoma City, OK 73104.

Received for publication 23 July 1991 and in revised form 18 November 1991.

J. Clin. Invest.

(C) The American Society for Clinical Investigation, Inc.

0021-9738/92/04/1236/06 \$2.00

Volume 89, April 1992, 1236-1241 considered crustacean counterparts of mammalian $P_{1}$ and $P_{2}$ (8). In addition, recent studies revealed that the ribosomal protein $\mathrm{L}_{12}$ is also a target of autoimmunity in SLE. This protein of molecular weight of $20 \mathrm{kD}$ is distinctive from the ribosomal $\mathrm{P}$ proteins (9).

SLE sera containing anti-P autoantibodies invariably show a strong cytoplasmic immunofluorescence pattern on fixed HeLa and mouse kidney cells due to the ribosomal, cytoplasmic distribution of $P$ proteins. In this study, we demonstrate by immunostaining techniques the presence of an epitope on the surface of several types of human cells that is antigenically related to the immunodominant carboxy terminus of P-proteins. Furthermore, we demonstrate by Western blot the presence of a $38-\mathrm{kD}$ protein, which is closely related or identical with ribosomal $\mathrm{P}_{0}$ protein, in plasma membranes isolated from human and animal cells.

Pathogenic effects of autoantibodies specific for intracellular components require cell destruction, release of antigen, and formation of phlogistic immune complexes. Such autoantibodies could also cause damage after penetration into live cells, a phenomenon that has been reported but remains controversial $(10,11)$. However, the presence of $P_{0}$ protein on the cell surface could trigger direct pathogenic mechanisms in the presence of anti-P autoantibodies.

\section{Methods}

Human anti-P sera. Human sera from patients with SLE were defined as having anti-P antibodies if they met the following three criteria: (a) precipitated purified ribosomes in a reaction of identity in gel diffusion with a monospecific prototype anti-P serum; $(b)$ reacted with a $38-\mathrm{kD}$ band in Western blot with purified rat ribosomes; and $(c)$ reacted in ELISA with plates coated with purified rat ribosomes and synthetic "P-peptide"-BSA conjugate.

Synthesis of "P-peptide". The carboxy-terminal 22-amino acid peptide of the ribosome P protein has the following sequence: Lys-LysGlu-Glu-Lys-Lys-Glu-Glu-Ser-Glu-Glu-Glu-Asp-Glu-Asp-Met-GlyPhe-Gly-Phe-Leu-Phe-Asp-OH (8). It was synthesized by a solid phase method, purified by HPLC and its composition confirmed by amino acid analysis $(12,13)$.

Synthetic "P-peptide"-BSA conjugate. $20 \mathrm{mg}$ of peptide and $40 \mathrm{mg}$ BSA were dissolved in $4 \mathrm{ml} 0.1 \mathrm{M} \mathrm{PO}_{4}$ buffer, $\mathrm{pH} 7.0 .2 .0 \mathrm{ml}$ of $0.25 \mathrm{M}$ glutaraldehyde were added dropwise with constant stirring. Blocking with lysine and dialysis were carried out as described previously (14).

Preparation of rat ribosomes. Ribosomes were prepared by a published method from a freshly prepared saline-perfused rat liver (15). The rat ribosome preparation precipitated strongly with sera with antiribosomal $\mathrm{P}_{0}$-positive sera by gel diffusion.

Ribosome-Sepharose column. Rat ribosome solution (14.0 $\mathrm{mg}$ protein $/ \mathrm{ml}$ ) was coupled to cyanogen bromide activated Sepharose according to the manufacturers' instructions (Pharmacia, Uppsala, Sweden). $11 \mathrm{~g}$ of Sepharose in a slurry was mixed with $175 \mathrm{mg}$ of ribosomal protein in $12.5 \mu \mathrm{l}$ coupling buffer. $68 \%$ of the added ribosomal protein was coupled to sepharose. 
Synthetic "P-peptide"-sepharose column. $20 \mathrm{mg}$ of synthetic "Ppeptide" was dissolved in $5 \mathrm{ml}$ of coupling buffer and added to $10 \mathrm{ml}$ of cyanogen bromide-activated Sepharose slurry. The coupling and blocking was carried out according to the manufacturers' instructions (Pharmacia).

Affinity purification of anti-P antibodies. Serum from SLE patient S.S. was selected and used in all the studies. This serum gave a single precipitin line and a reaction of identity in gel diffusion when reacted with purified rat ribosomes and calf thymus extract. It also precipitated strongly with synthetic "P-peptide"-BSA conjugate but not with free BSA. $1 \mathrm{ml}$ of S.S. serum was passed over the ribosome-Sepharose column or the synthetic "P-peptide"-Sepharose column. After washing, columns were eluted with $3 \mathrm{M} \mathrm{MgCl}_{2}$. Eluates containing purified antibodies were dialyzed versus PBS, and reconcentrated to the original volume of serum. The unretained fractions from such columns were further absorbed by adding incremental amounts of purified rat ribosomes until no further precipitate formed. This was designated "depleted" serum. Such a depleted serum at a $1 / 100$ dilution developed a net OD of 0.2 in a micro-ELISA using ribosome-coated plates whereas unabsorbed serum developed an OD of 0.2 at a dilution of $10^{-5}$ suggesting the removal of $99.9 \%$ of antibody activity. Specifically purified antibodies from either the rat ribosome column or the synthetic "Ppeptide" column were highly active in precipitin reactions with rat ribosomes or in ELISA with rat ribosome-coated plates.

Cell culture. Cell lines were purchased from American Type Culture Collection (ATCC, Rockville, MD) and cultured according to ATCC instructions. These include human hepatoma cells HepG2 (ATCC-B8065) grown in Eagle's MEM supplemented with 10\% FBS and human neuroblastoma cells SK-N-MC (ATCC-HTB10) grown in MEM supplemented with $10 \%$ FBS. Human fibroblasts were isolated from skin biopsy material of an asymptomatic male donor according to the method of Vijg et al. (16) and grown in MEM supplemented with $10 \%$ FBS.

Immunofluorescent staining. Cell monolayers grown in T-75 flasks were washed in sterile PBS two times and incubated with trypsinEDTA solution $(0.25 \%$ trypsin, $0.02 \%$ EDTA in PBS) for $5 \mathrm{~min}$ at $37^{\circ} \mathrm{C}$. Trypsinization was stopped by addition of $5 \mathrm{ml}$ FBS per flask. This was followed by vigorous pipetting to detach the cells. After 10 min of centrifugation at $400 \mathrm{~g}$ supernates were discarded and pellets were resuspended in respective media. Cell suspensions were adjusted to the concentration of $5 \times 10^{4}$ cells $/ \mu$ and seeded into eight-chamber cell culture slides (Labtech, Naperville, IL). After 2-4 d of growth (depending on the cell line) cells reached semiconfluency and were used for immunofluorescent staining. The staining was carried out on fixed cells at $25^{\circ} \mathrm{C}$ and on native cells at $0-4^{\circ} \mathrm{C}$. Cells were washed three times with $\mathrm{PBS}$ for staining at $25^{\circ} \mathrm{C}$ and fixed $(1 \mathrm{~h})$ with $0.5 \%$ paraformaldehyde. Fixation was followed by a 10 -min incubation with $0.2 \%$ Triton X-100 (Sigma Chemical Co., St. Louis, MO) and a triple washing with PBS. After this treatment cells were incubated with whole serum, antibodies purified by the use of ribosome column, antibodies eluted from an immunoaffinity column containing synthetic "P-peptide" and with serum adsorbed with rat liver ribosomes. Incubation was carried out at $25^{\circ} \mathrm{C}$ for $3 \mathrm{~h}$. After triple washing with PBS, cells were incubated with FITC-labeled antibodies to human immunoglobulins for $2 \mathrm{~h}$ at $25^{\circ} \mathrm{C}$. After three washes with PBS, plastic chambers and gaskets were removed from slides. A few drops of 50\% glycerol diluted with PBS were added to each slide. Coverslips were carefully placed on each slide which made them ready for microscopic analysis. For the long-term storage slides were kept at $-20^{\circ} \mathrm{C}$, in dark, up to several months with no appreciable loss in fluorescence or change in cell morphology. Whole serum from an asymptomatic, healthy male donor was used as a negative control.

To stain native cells, slides were placed on ice for $10 \mathrm{~min}$ and washed with ice-cold PBS three times. Immediately after washing, cells were incubated with antibodies identical to those used for staining of fixed cells. The incubation lasted for $3 \mathrm{~h}$ at $0-4^{\circ} \mathrm{C}$ and was followed with triple washing with ice-cold PBS and a 2-h incubation with FITClabeled antibodies to human immunoglobulins at $0-4^{\circ} \mathrm{C}$. After a final washing with ice-cold $3 \times$ PBS cells were fixed with ice-cold $0.5 \%$ paraformaldehyde for $1 \mathrm{~h}$ at $0-4^{\circ} \mathrm{C}$. Glycerol and coverslips were placed on each slide as described above.

Fluorescence microscopy. Slides were analyzed for immunofluorescence by the use of an epifluorescent/phase contrast microscope (Optiphot; Nikon, Garden City, NJ) equipped with a photometer (Nikon, UFX) and an automated camera (Nikon, FX-35A). A 20X objective with high numerical aperture (NA 0.75 ) was routinely used.

Confocal microscopy. To accurately analyze immunofluorescence pattern of native cells stained at $0-4^{\circ} \mathrm{C}$, a laser scanning confocal microscope (Zeiss, Jena, Germany) was used. Cells were excited at $488 \mathrm{~nm}$ with 2.5-W argon ion laser and subjected to optical sectioning going stepwise from the cell surface adhering to the slide towards the apical cell surface and using a $1.0-\mu \mathrm{m}$ step size.

Immunogold staining and electron microscopy. A monolayer of HepG2 cells grown in T-75 flask was washed with PBS three times and fixed with $0.5 \%$ paraformaldehyde for $1 \mathrm{~h}$. After fixation and additional washing, cells were scraped with a rubber policeman in PBS and centrifuged for $10 \mathrm{~min}$ at $400 \mathrm{~g}$. The pellet was embedded with an epoxy resin followed by preparation of ultrathin $(1 \mu \mathrm{m})$ sections according the method described by Hayat (17). After mounting to copper grids, sections were incubated at $25^{\circ} \mathrm{C}$ with anti-P autoantibody purified over a column with synthetic "P-peptide". Incubation was carried out for $2 \mathrm{~h}$ with copper grids floating on top of $10 \mu \mathrm{l}$ antibody containing droplets. After five washes with PBS, grids were incubated for $2 \mathrm{~h}$ with goat anti-human IgG conjugated to $5 \mathrm{~nm}$ gold particles (Sigma Chemical Co.). This was followed by washing and analysis under JEOL's JEM1200 EX electron microscope (JEOL, Tokyo, Japan). Grids incubated with serum from an asymptomatic male donor followed by immunogold conjugate served as controls.

Isolation of plasma membranes. Cells were grown in T-150 flasks until confluent. $18-20 \mathrm{~h}$ before membrane isolation, fresh medium was added. 10-15 flasks were routinely used per experiment. The isolation procedure started with washing of cell monolayers in PBS $(3 \times)$ followed by a 15 -min incubation in ice-cold PBS ( $20 \mathrm{ml} /$ flask). From this point on the entire procedure was carried out at $0-4^{\circ} \mathrm{C}$. Cold PBS was discarded and $10 \mathrm{ml}$ of lysis medium ( $1 \mathrm{mM} \mathrm{NaHCO}_{3}, \mathrm{pH} 8.3$ ) was added to each flask. After a 2-min rotation on an orbital shaker the lysis medium was discarded. This step was repeated one more time and the cells were harvested in $10 \mathrm{ml}$ of lysis medium containing protease inhibitors ( $5 \mathrm{mM}$ PMSF and $5 \mathrm{mM}$ EDTA). Scraped cells were homogenized in a glass homogenizer. The homogenate was centrifuged for $20 \mathrm{~min}$ at $28,000 \mathrm{~g}$. The resulting pellet was resuspended in $8 \mathrm{ml}$ of $10 \%$ sucrose. Discontinuous gradient gel consisting of $8 \mathrm{ml}$ of $50 \%$ sucrose at the bottom, $8 \mathrm{ml}$ of $38 \%$ sucrose in the middle and $8 \mathrm{ml}$ of $27 \%$ sucrose on the top were prepared in $35-\mathrm{ml}$ polycarbonate tubes. After layering 8 $\mathrm{ml}$ of resuspended cell pellet on top of the gradient, tubes were centrifuged in a "swing-out" rotor (model SW-27; Beckman Instruments, Palo Alto, CA) for $2 \mathrm{~h}$ at 76,000 $\mathrm{g}$ in an L3-50 ultracentrifuge (Beckman Instruments). The plasma membrane band, usually positioned $1.5 \mathrm{~cm}$ from the top of the gradient, was recovered with a transfer pipette and diluted in $5 \mathrm{vol}$ of PBS. This was followed by a $25-\mathrm{min}$ centrifugation at 70,000 g. The final pellet was resuspended in PBS and kept at $-80^{\circ} \mathrm{C}$. As revealed by EM, the described preparation consisted of bilayer vesicles of variable sizes with no detectable ribosomes or other subcellular organeles even at the magnification of 100,000 . The lack of ribosomal contamination in membrane samples was confirmed by determination of the ribose content using conventional Orcinol reaction (18). The average concentration of ribose in isolated membranes was below $0.1 \mu \mathrm{mol} / \mathrm{mg}(n=3)$ protein. By the same analysis ribose concentration was $5.4 \pm 0.7(n=3) \mu \mathrm{mol} / \mathrm{mg}$ of protein in isolated rat ribosomes. To prepare plasma membranes from animal kidneys, fresh organs from sheep, dog, and rat were minced and separately treated with collagenase for $30 \mathrm{~min}$ at $37^{\circ} \mathrm{C}$ with occasional gentle shaking. After filtration through a $200-\mu \mathrm{m}$ nylon mesh, fibrous residue and large cell aggregates were discarded. Homogenous cell suspensions were washed with PBS three times and processed for membrane isolation as described for cultured cells. 
Immunoblotting. Electrophoresis of rat ribosomal and various membrane preparations on SDS-polyacrylamide gels, electrotransfer to nitrocellulose membranes as well as incubation with anti-P antibodies were carried out by a method described previously (19).

\section{Results}

Immunofluorescence analysis. All analyzed cells showed strong cytoplasmic immunofluorescence after fixation, treatment with Triton $\mathrm{X}-100$, and staining with anti-P antibodies at $25^{\circ} \mathrm{C}$. This applies to anti-P whole serum, ribosome specific as well as synthetic "P-peptide" specific antibodies. Whole serum

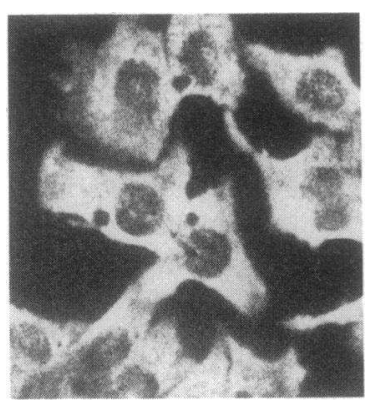

A
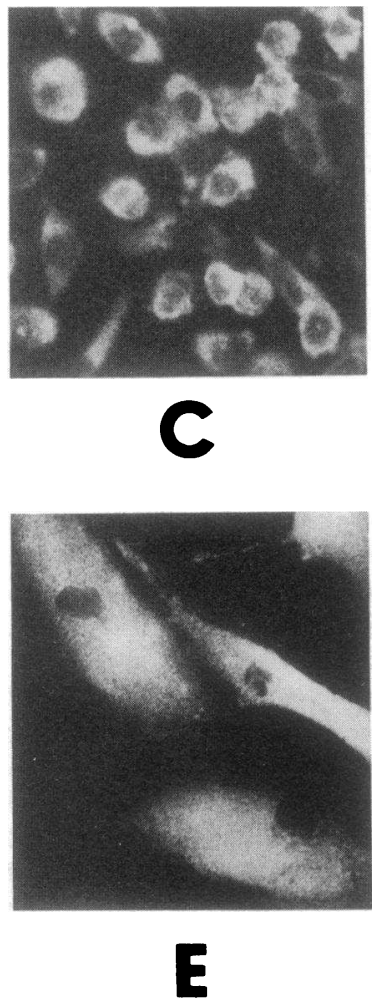

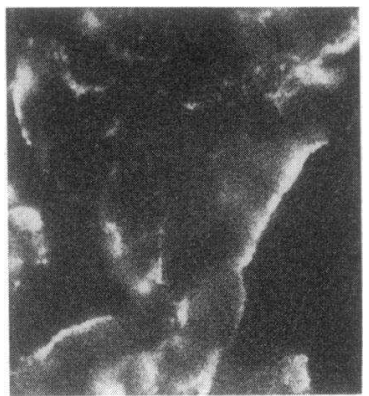

B

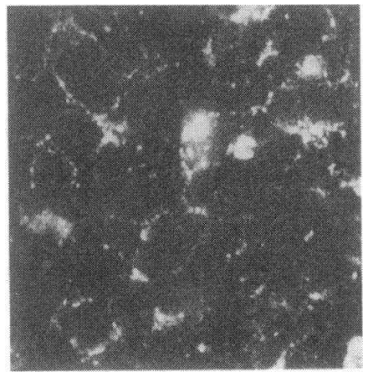

D
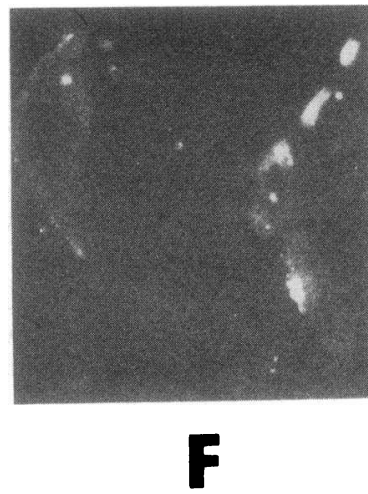

Figure 1. Indirect immunofluorescence analysis of human hepatoma cells (HepG2), human neuroblastoma cells ( $S K-N-M c)$, and human fibroblasts stained with an affinity-purified anti-"P-peptide" autoantibody. Fixed cells show strong cytoplasmic fluorescence with dark nuclei in case of all three types of cells, i.e., $(A)$ HepG2, $(C)$ SK-N-Mc, and $(E)$ fibroblasts. Staining of native cells at $0-4^{\circ} \mathrm{C}$ resulted in strong surface fluorescence in the case of $(B)$ HepG2 cells, moderate surface fluorescence in the case of $(D)$ SK-N-Mc cells, and weak surface fluorescence in the case of $(F)$ fibroblasts.

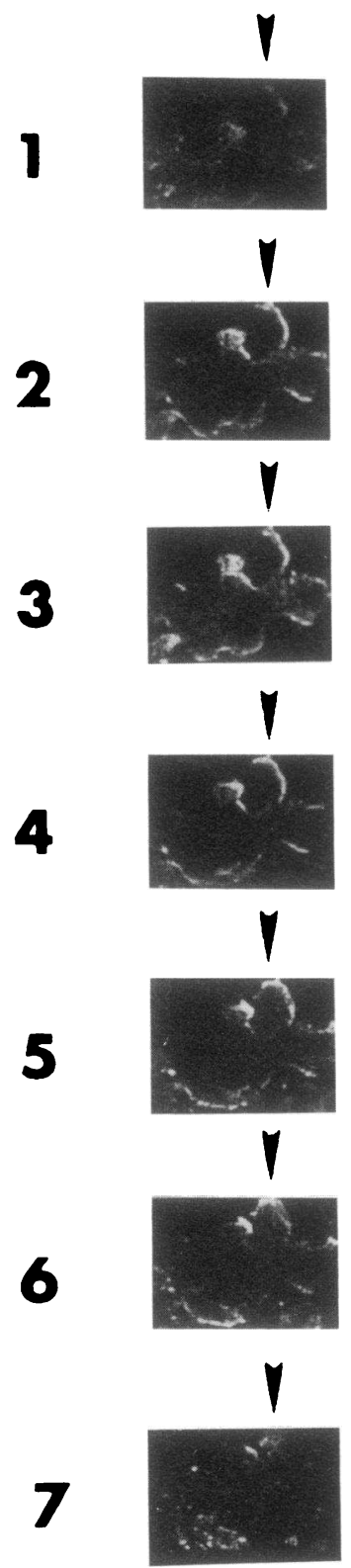

Figure 2. Confocal microscopy of native HepG2 cells stained with immunoaffinity purified "anti-peptide" antibody at $0-4^{\circ} \mathrm{C}$. Optical sections $(1-$ 7) were taken in sequence from the surface adhering to the slide ( 1 ) to the apical surface of the cell (7) using 1.0 $\mu \mathrm{m}$ step size. The cell marked with the arrow exemplifies an immunofluorescence pattern typical of a surface staining. The bottom (frames 1 and 2) as well as midsection (frames 3,4 , and 5) clearly demonstrate ringshaped fluorescence, whereas the top of the cell (frames 6 and 7) shows rather "granular" fluorescence covering a circular area. A three-dimensional model of described fluorescence pattern is consistent with a "domelike" structure. Obviously, the bottom surface of the cell adhering to the slide was not accessible to antibodies, whereas the sides and top were fully exposed. This observation applies to other cells shown on scans $1-7$. However, they do not appear to be laid in a perfectly even monolayer.

depleted of anti-P antibodies showed no fluorescence with any of the cells. Staining of native cells at $0-4^{\circ} \mathrm{C}$ clearly showed typical surface immunofluorescence pattern in the case of hepatoma cells (HepG2) and neuroblastoma cells. Fibroblasts showed negligible surface immunofluorescence irrespective of the type of anti-P antibody used (Fig. 1). Surface fluorescence of native HepG2 cells stained with antibodies purified over synthetic "P-peptide" column was confirmed by the use of confocal microscopy (Fig. 2).

Therefore, cytoplasmic expression of $P$ antigen appears to be comparable in all analyzed cells. The surface expression of this antigen, however, is not equal in all cells. Hepatoma cells are the most abundant in the surface $P$ antigen followed by neuroblastoma cells. Fibroblasts appear to be poor in membrane-associated $\mathrm{P}$ antigen.

EM analysis. Since hepatoma cells expressed highest surface fluorescence with anti-P antibodies they were further analyzed by electron microscopy. Immunogold staining with antibodies purified over synthetic "P-peptide" column revealed 
two patterns of binding of these antibodies to the outer surface of cell membrane. Gold particles were distributed more or less evenly over "flat" and relatively long sections of cell surface whereas in coated pits they appeared localized in clusters. In addition to the surface distribution, numerous gold particles were also localized inside cells due to exposure of the cytoplasmic pool of antigen in sectioned cells (Fig. 3).

Western blotting. To explore the molecular nature of the cell surface antigen reacting with anti-P antibodies, plasma membranes were purified from cultured human hepatoma cells and from tissues of freshly isolated sheep, dog, and rat kidneys. SDS-PAGE under reducing conditions followed by immunoblotting clearly showed in all plasma membranes the presence of a protein band strongly reactive with anti-P antibodies. This applies to the whole anti-P antiserum, purified antibody from ribosome column, and to the antibody eluted from synthetic "P-peptide" column. No reaction was observed with depleted anti-P antiserum or normal human serum. Electrophoretic mobility of this plasma membrane protein was identical to the mobility of $38-\mathrm{kD} \mathrm{P}_{0}$ protein present in rat liver ribosomes. Interestingly, plasma membranes showed a single 38-kD band with anti-P antibodies whereas rat liver ribosomes gave positive bands corresponding to $38-k\left(P_{0}\right), 19-\left(P_{1}\right), 17-$ $\left(\mathrm{P}_{2}\right)$, and $50-\mathrm{kD}$ proteins (Fig. 4). Four separate Western blot analysis of the HepG2 cell culture supernates showed no detectable P proteins demonstrating the lack of "shedding" or leakage of these antigens from the cells. These data strongly support the presence in the plasma membrane of a $38-\mathrm{kD}$ polypeptide antigenically related to or identical with the ribosomal $38-\mathrm{kD}$ $P_{0}$ protein.

\section{Discussion}

Data are presented which show that a polypeptide antigenically related to the $38-\mathrm{kD}$ ribosomal $P_{0}$ protein is present on the surface of several types of human and animal cells as revealed by their reactivity with purified anti-P autoantibodies. Of interest is the apparent differential membrane expression of this protein in that the surface of hepatoma cells and neuroblastoma cells react strongly with the autoantibodies, whereas fibroblasts react weakly with the same autoantibody preparations. Immunogold staining indicates an even as well as clustered distribution of this antigen on the surface of hepatoma cells. It remains to be seen whether or not other cells have similar pattern(s). In addition to immunofluorescence and immunogold analyses, Western blotting of highly purified plasma membranes show strong and highly selective reactivity with the autoantibodies as they carry a $38-\mathrm{kD}$ polypeptide antigenically related if not identical to the ribosomal $P_{0}$ protein. Interestingly the membrane preparation did not possess detectable quantities of the other two ribosomal $P$ proteins, i.e., the $19-k D P_{1}$ and $17-\mathrm{kD} \mathrm{P}_{2}$.

According to the currently assumed model, $P_{0}$ is attached to the large ribosomal subunit and serves as an anchor for the pentameric complex consisting of one $\mathrm{P}_{0}$ molecule combined with two $P_{1}$ and $P_{2}$ homodimers (20-23). This complex of $P$
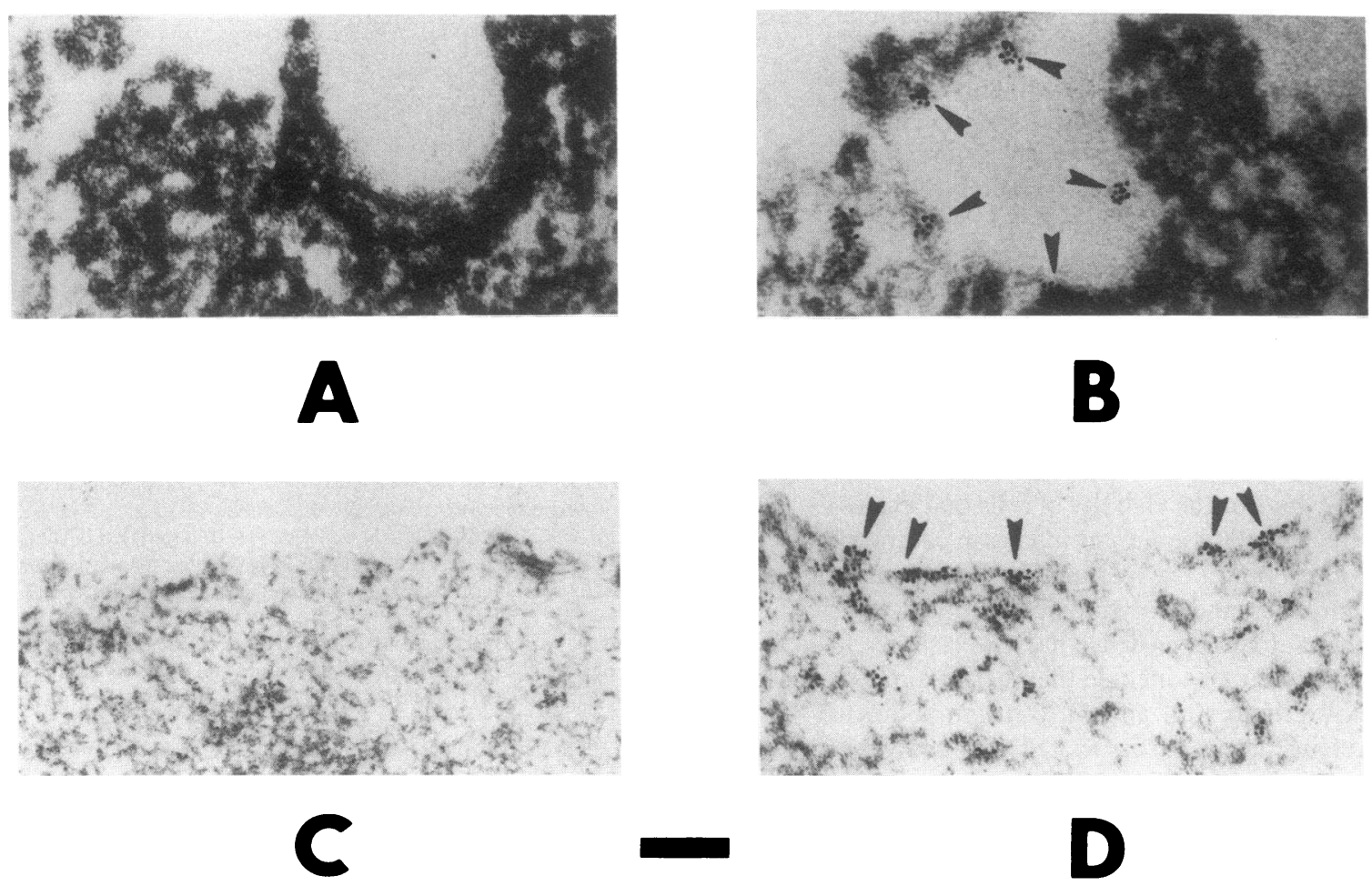

Figure 3. Immunogold electron microscopic analysis of human hepatoma cells (HepG2) stained with an affinity-purified anti-"P-peptide" autoantibody. Clusters of gold particles can be seen on the outer surface of a coated pit $(B$, arrows). On the surface of a "flat" section of the cell gold particles are more evenly distributed ( $D$, arrows). Considerable number of gold particles can be seen inside cell membrane in both cases. $A$ and $C$ represent respective controls stained with serum from an asymptomatic healthy male. Both of these controls were virtually free of gold particles confirming specificity of the staining with anti-"P-peptide" autoantibody. Bar, $100 \mathrm{~nm}$. 


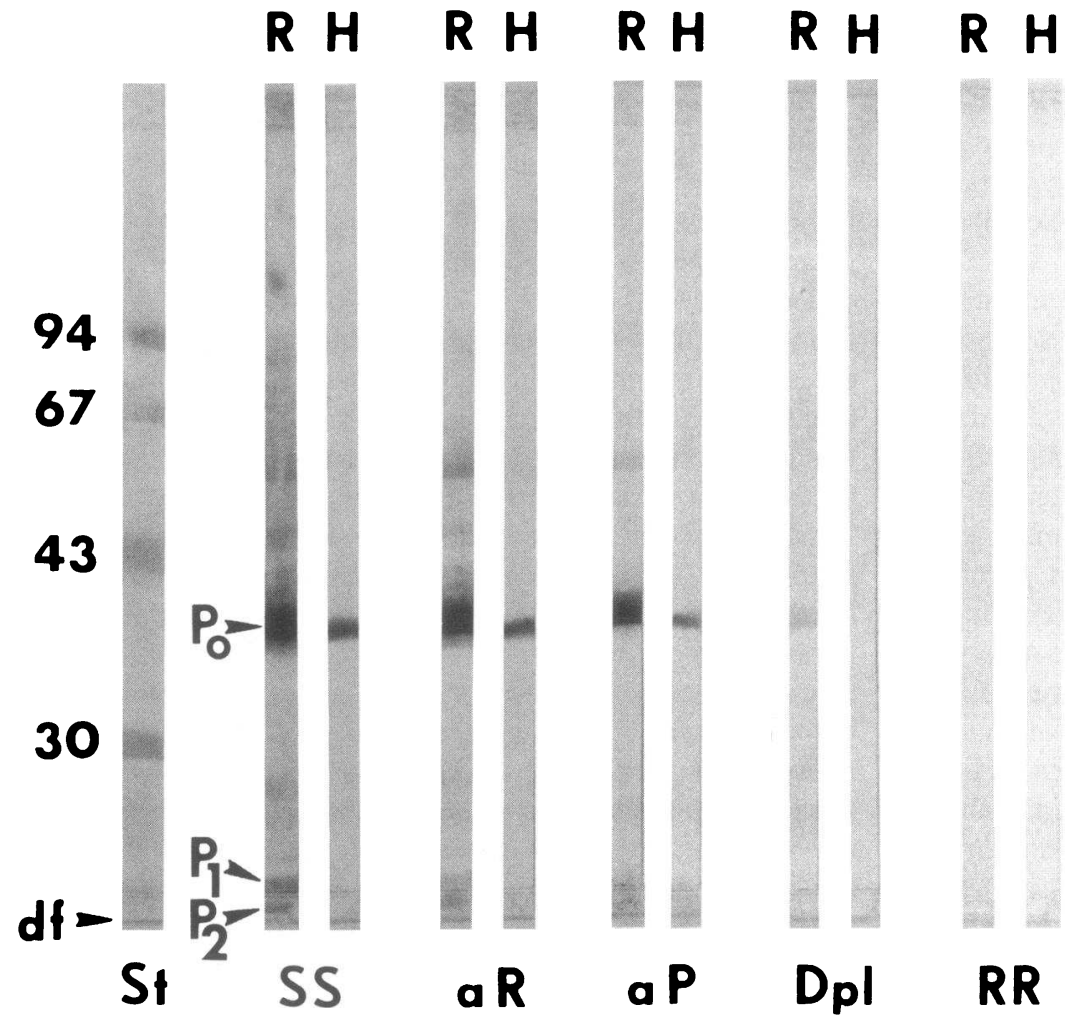

Figure 4. Western blot analysis of rat ribosomes $(R)$ and human hepatoma cell (HepG2) plasma membrane $(H)$. Electrophoretic separation was carried out on SDS polyacrylamide gel under reducing conditions. After transfer to the nitrocellulose the blots were stained with SLE serum containing anti-P autoantibodies $(S S)$; anti-P autoantibodies purified over a rat ribosome affinity column $(a R)$; anti-P autoantibodies purified over a synthetic "P-peptide" affinity column $(a P)$; serum depleted of anti-P autoantibodies $(D p l)$ and with serum from asymptomatic healthy male donor $(R R) . \mathrm{St}=$ molecular weight standards representing $94 \mathrm{kD}(94), 67 \mathrm{kD}(67), 43 \mathrm{kD}(43)$ and $30 \mathrm{kD}$ (30) proteins. $d f$, dye front. The blots of rat ribosomes $(R)$ clearly show all three ribosomal $\mathrm{P}$ proteins, i.e., 38-kD $\mathrm{P}_{0}$ protein $\left(P_{0}\right)$; $19-\mathrm{kD} \mathrm{P}_{1}$ protein $\left(P_{1}\right)$ and 17 kD $\mathrm{P}_{2}$ protein $\left(P_{2}\right)$ visualized with all three types of anti-P autoantibodies. The blots of human hepatoma cell plasma membrane show only the $\mathrm{P}_{0}$ band. Depleted SLE serum visualized trace of $P_{0}$ on the rat ribosome blot whereas no staining is visible on the hepatoma membrane blot. Plasma membranes isolated from sheep, dog, and rat kidneys stained with anti-P antibodies revealed $P_{0}$ band identical to that of human hepatoma cell plasma membrane although somewhat variable and less intense. No bands are visible on blots stained with control serum from a healthy donor. proteins is involved in the interaction of EF-1 $\alpha$ and EF-2 with ribosomes since $\mathrm{mAbs}$ to $\mathrm{P}$ proteins inhibit binding of these elongation factors to ribosomes (24). $P$ proteins have also been found in the cytosolic fraction of HeLa cells (8) as well as in the cytoplasmic pool of Artemia (6). These data, however, offer no clues to the possible mechanism by which $\mathrm{P}_{0}$ could find its way to the cell surface and make its $\mathrm{COOH}$-terminal domain accessible to the anti-P autoantibodies. Particularly abundant expression of $\mathrm{P}_{0}$ on the surface of HepG2 cells could be related to their metabolic activity. These cells are known for highly active synthesis of many proteins (25-29) and have also been used as a good model for the phosphorylation of ribosomal proteins (30).

The clinical significance of our findings lies in the expansion of the possible participation of anti-P autoantibodies in disease expression. The availability of the reactive peptide on the surface of cells makes possible the direct effect of autoantibodies on the function and/or the viability of cells that express this antigenic target. A role of these autoantibodies in pathogenesis and disease expression awaits experiments demonstrating such functional modulation and/or cytotoxic effects as well as in vivo binding. Other autoantigens which have been shown to be represented as the cell surface include the nuclear antigens chromatin (31), DNA receptor (32), and $\mathrm{Ku}$ (33). Antibodies to the ribosomal $\mathrm{P}$ proteins have been associated with neuropsychiatric disease in lupus patients (34). Most recently, specific depletion of anti-P autoantibodies in cerebrospinal fluid per milligram IgG relative to the serum concentration of anti-P per milligram IgG has been reported (2). This finding is consistent with specific uptake and/or binding of anti-P antibodies to the cells of the central nervous system. The presence of $P$ antigen on the surface of cells of neural origin described in this report provides a realistic setting for such possibilities. The presence of $P$ antigen on the surface of other cells (e.g., hepatocyte, fibroblast, kidney cell) also enlarges the spectrum of potential targets in pathogenesis of SLE patients.

\section{Acknowledgments}

Confocal microscopy analyses were carried out at the Fluorescence Imaging Center, Oklahoma Center for Molecular Medicine, under the guidance of Dr. Robert D. Fugate.

This study was supported by National Institutes of Health grants RO1-AR31133 and RO1-AI215681 and by resources of the Oklahoma Medical Research Foundation.

\section{References}

1. Bonfa, E., and K. B. Elkon. 1986. Clinical and serologic associations of the antiribosomal P protein antibody. Arthritis Rheum. 29:981-985.

2. Schneebaum, A. B., J. D. Singleton, S. G. West, J. K. Blodgett, L. G. Alley, J. C. Cheronis, and B. L. Kotzin. 1991. Association of psychiatric manifestations with antibodies to ribosomal P proteins in systemic lupus erythematosus. $\mathrm{Am}$. J. Med. 90:54-62.

3. Van Agthoven, A. J., J. P. Massen, and W. Moller. 1977. Structure and phosphorylation of an acidic protein from $60 \mathrm{~S}$ ribosomes and its involvement in elogation factor-2 dependent GTP hydrolysis. Biochem. Biophys. Res. Commun. 77:989-998.

4. Tsurugi, K., E. Collatz, K. Todokoro, N. Ulrich, H. N. Lightfoot, and I. G. Wool. 1978. Isolation of eukaryotic ribosomal proteins. J. Biol. Chem. 253:946955.

5. Van Agthoven, A., Y. Kriek, R. Amous, and W. Möller. 1978. Isolation and characterization of the acidic phosphoparotein of 60-S ribosomes from artemia salina and rat liver. Eur. J. Biochem. 91:553-565.

6. Towbin, H., H. P. Ramjone, H. Kuster, D. Liverani, and J. Gordon. 1982 Monoclonal antibodies against eukaryotic ribosomes. Use to characterize a ribosomal protein not previously identified and antigenically related to the acidic phosphoproteins P1/P2. J. Biol. Chem. 257:12709-12715. 
7. Elkon, K. B., A. P. Parnassa, and C. L. Foster. 1985. Lupus autoantibodies target ribosomal P proteins. J. Exp. Med. 162:459-471.

8. Elkon, K., S. Skelly, A. Parnassa, W. Möller, W. Danko, H. Weissbach, and N. Brot. 1986. Identification and chemical synthesis of a ribosomal protein antigenic determinant in systemic lupus erythematosus. Proc. Natl. Acad. Sci. USA. 83:7419-7423.

9. Sato, T., T. Uchiumi, R. Kominami, and M. Arakava. 1990. Autoantibodies specific for the 20-KDal ribosomal large subunit protein L12. Biochem. Biophys. Res. Commun. 172:496-502.

10. Alarcon-Segovia, D., A. Ruiz-Argulles, and E. Fishbein. 1978. Antibody to nuclear ribonucleoprotein penetrates live human mononuclear cells through Fc-receptors. Nature (Lond.). 271:67-69.

11. Alarcon-Segovia, D., A. Ruiz-Argulles, and L. Florerite, 1979. Antibody penetration into living cells. J. Immunol. 122:1855-1862.

12. Carpino, L. A., and G. Y. Han. 1972. The 9, flouroenylmethylcarbonyl amino protecting group. J. Org. Chem. 37:3404-3409.

13. Mahoney, W. C., and M. H. Hermodson. 1980. Separation of large denatured peptides by reverse phase high performance, liquid chromatography, trifluoracetic acid as a peptide solvent. J. Biol. Chem. 255:11199-11203.

14. Reichlin, M. 1980. Use of glutoraldehyde as a coupling agent for proteins and peptides. Methods Enzymol. 70:159-165.

15. Moldave, K., and I. Sadnik. 1979. Preparation of derived and native ribosomal subunits from rat liver. Methods Enzymol. LIX:402-410.

16. Vijg, J., E. Mullaart, F. Berends, P. H. M. Lohman, and D. L. Knook. 1986. UV-induced DNA excision repair in rat fibroblasts during immortalization and terminal differentiation in vitro. Exp. Cell. Res. 167:517-530.

17. Hayat, M. A. 1986. Basic Techniques for Transmission Electron Microscopy. Academic Press, New York. 56-181.

18. Horecker, B. L. 1957. The orcinol reaction for mixtures of pentose and heptulose. Methods Enzymol. 3:105-107.

19. Itoh, Y., M. D. Rader, and M. Reichlin. 1990. Heterogeneity of the Ro/ SSA antigen and autoantiRo/SSA response: evidence of the four antigenically distinct forms. Clin. Exp. Immunol. 81:45-51.

20. Lee, C. C., C. R. Cantor, and B. Wittmann-Liebold. 1981. The number of copies of ribosome-bound proteins L7 and L12 required from protein synthesis activity. J. Biol. Chem. 256:41-48.

21. Möller, W., P. I. Schrier, J. A. Maassen, A. Zantema, E. R. H. Schop, H Reinalda, A. F. M. Cremers, and J. E. Mellema. 1983. Ribosomal proteins L7/ L12 of escherichia coli. Localization and possible molecular mechanism in translation. J. Mol. Biol. 163:553-573.

22. Uchiumi, T., A. J. Wahba, and R. R. Traut. 1987. Topography and stoichi- ometry of acidic proteins in large ribosomal subunits from artermia salina as determined by crosslinking. Proc. Natl. Sci. USA. 84:5580-5584.

23. Casiano, C., A. T. Matheson, and R. R. Traut. 1990. Occurrence in the archaebacterium sulfolobus solfataricus of a ribosomal protein complex corresponding to escherichia coli $(\mathrm{L} 7 / \mathrm{L} 12)_{4} \cdot \mathrm{L} 10$ and eukaryotic $(\mathrm{P} 1)_{2} /(\mathrm{P} 2)_{2} \cdot \mathrm{PO} . J$ Biol. Chem. 265:18757-18761.

24. Uchiumi, T., R. R. Traut, and R. Kominami. 1990. Monoclonal antibodies against acidic phosphoproteins P0, P1 and P2 of eukaryotic ribosomes as functional probes. J. Biol. Chem. 265:89-95.

25. Knowles, B. B., C. C. Howe, and D. P. Aden. 1980. Human hepatocellular carcinoma cell lines secrete the major plasma proteins and hepatitis B surface antigen. Science (Wash. DC). 209:497-499.

26. Schwartz, A. L., S. E. Fridovich, B. B. Knowles, and H. F. Lodish. 1981 Characterization of the asialoglycoprotein receptor in a continous hepatoma line. J. Biol. Chem. 256:8878-8881.

27. Morris, K. M., G. Goldberger, H. R. Colten, D. P. Aden, and B. B Knowles. 1982. Biosynthesis and processing of a human precursor complement protein, Pro-C3, in a hepatoma derived cell line. Science (Wash. DC). 215:399400.

28. Koren, E., W. J. McConathy, A. G. Lacko, and B. B. Knowles. 1985. Detection of lecithin:cholesterol acyltransferase (LCAT) in a human hepatoma cell line. Cancer Biochem. Biophys. 7:301-307.

29. Dashti, N., P. Alaupovic, C. Knight-Gibson, and E. Koren. 1987. Identification and partial characterization of discrete apolipoprotein B containing particles produced by human hepatoma cell line HepG2. Biochemistry. 26:48374846.

30. Abraham, A. K., and M. S. Khatim. 1989. Kinetics of ribosomal protein S6 phosphorylation by HepG2 cells in response to insulin. Biochem. Biophys Res. Commun. 161:797-802.

31. Holers, V. M., and B. L. Kotzin. 1985. Expression of nuclear antigens on the cell surface of human peripheral blood mononuclear cells. J. Clin. Invest. 76:991-998.

32. Bennett, R. M., B. L. Kotzin, and M. J. Merritt. 1987. DNA receptor dysfunction in systemic lupus erythematosus and kindred disorders. J. Exp. Med. 166:850-863.

33. Prabhakar, B. S., G. P. Allaway, J. Srinivasappa, and A. L. Notkins. 1990. Cell surface expression of the $70-\mathrm{kD}$ component of $\mathrm{Ku}$, a DNA binding nuclear autoantigen. J. Clin. Invest. 86:1301-1305.

34. Bonfa, E., S. J. Golombek, L. D. Kaufman, S. Skelly, H. Weisbach, N. Brot, and K. Elkon. 1987. Association between lupus psychosis and antiribosomal P protein antibodies. N. Engl. J. Med. 317:265-271. 